\title{
Depression and Its Contributing Factors; A Study among Staff of An Academic Institution in Malaysia
}

\author{
Salmi Razali1',2, Chua Yung-An², Mohd Izwan Mat Nazali'1, Hapizah M Nawawi² \\ 1 Department of Psychiatry, \\ 2 Institute of Pathology, Laboratory and Forensic Medicine (I-PPerForM) \\ Faculty of Medicine, \\ Universiti Teknologi MARA, 47000 Sungai Buloh, Selangor, Malaysia \\ drsalmi@gmail.com; yungan.chua@gmail.com; dr.izwan.pro@gmail.com; hapizah.nawawi@gmail.com \\ Tel. 03-61265000
}

\begin{abstract}
Information on depression and its contributing factors among the staff of the academic institution is sparse. Hence, this study aimed to determine the prevalence of depression among them and investigate its contributing factors. We used the Depression, Anxiety and Stress Scale 21-item and pro forma questionnaires to assess the presence of depression, sociodemographic factors, personal factors and job-related factors. Of 278 participants, $27.7 \%$ had clinical depression. Contributing factors include inadequate workplace facilities, low-tier job category, working in urban campus and low income. Addressing factors underpin depression among staff in the academic institution is crucial to ensure early interventions can be offered.
\end{abstract}

Keywords: Depression; Academic Institution; Workers; Contributing Factors

eISSN: 2398-4287 @ 2019. The Authors. Published for AMER ABRA cE-Bs by e-International Publishing House, Ltd., UK. This is an open access article under the CC BYNC-ND license (http://creativecommons.org/licenses/by-nc-nd/4.0). Peer-review under responsibility of AMER (Association of Malaysian Environment-Behaviour Researchers), ABRA (Association of Behavioural Researchers on Asians) and cE-Bs (Centre for Environment-Behaviour Studies), Faculty of Architecture, Planning \& Surveying, Universiti Teknologi MARA, Malaysia.

DOI: https://doi.org/10.21834/e-bpj.v4i12.1894

\subsection{Introduction}

World Health Organization (2019) estimated that more than 300 million people worldwide are currently suffering from depression. Within a decade, from 2005 until 2015, WHO showed a striking 18\% leap of the global prevalence of depression. In Malaysia, the National Health and Morbidity Survey (NHMS, 2015) reported almost a threefold increase in mental health issues among adult Malaysians between 1996 until 2015. Citing a relatively recent review on depression by Ng (2014), Clinical Practice Guideline (CPG) of the management of the depressive disorder, Ministry of Health Malaysia (2019) showed that the percentage of depression in Malaysia varies from $8 \%$ to $12 \%$. While mental health issues are increasing nationwide, a local study by Noor and Ismail (2016) showed depression among academic staff in the higher institution are three times higher than the local population, which is about $35.4 \%$ of these staff have depression (Noor \& Ismail, 2016).

It is a concern that consequences of depression on the mental health status of the staff in higher education are likely to cause damaging effects not only to the quality of life of the staff and students, but also the success of the institution (January et al., 2018). Depression results in absenteeism and presenteeism; in both situations, the total effects are a reduction in job performance and work productivity (Lerner \& Henke, 2008). Furthermore, intricate effects of personal issues and continuous exposure to job stress, work-life imbalance and poor access to appropriate intervention may worsen depression, leading to severe complications such as suicide and psychosis (Milner, Witt, LaMontagne, \& Niedhammer, 2018).

Depression is believed to be attributable to the interaction between complex biological, psychological, social and environmental factors (Lammerts et al., 2016). Hence, depression among academic staff should not merely be regarded as a workplace or job stress

eISSN: 2398-4287 @ 2019. The Authors. Published for AMER ABRA cE-Bs by e-International Publishing House, Ltd., UK. This is an open access article under the CC BYNC-ND license (http://creativecommons.org/licenses/by-nc-nd/4.0). Peer-review under responsibility of AMER (Association of Malaysian Environment-Behaviour Researchers), ABRA (Association of Behavioural Researchers on Asians) and cE-Bs (Centre for Environment-Behaviour Studies), Faculty of Architecture, Planning \& Surveying, Universiti Teknologi MARA, Malaysia. DOI: https://doi.org/10.21834/e-bpj.v4i12.1894 
issues (Noor \& Ismail, 2016). Workers have their personal and family issues which could additionally precipitate depression at work (Fan, Blumenthal, Watkins, \& Sherwood, 2015). In the working environment, disturbance in the dynamic of interaction between job demand, control and support plays a crucial role in the genesis of psychological and emotional disturbances among workers (Karasek Jr, 1979; Van der Doef \& Maes, 1999).

In Malaysia, despite the increase in the local prevalence of depression and overwhelming negative consequences, there is still sparse of knowledge of the level of depression among academic staff and its contributing factors. Most previous local research on academic staff have focused mainly on job stress, job satisfaction and burnout but little on depression (Ahsan, Abdullah, Fie, \& Alam, 2009; Ismail, Yao, \& Yunus, 2009; Mustapha, 2013; Noordin \& Jusoff, 2009). Previous local studies among staff in academic institutions also focused only on academicians without investigating the non-academic and support staff. Moreover, little is known regarding the contributions of personal and family matters on depression among them. Hence, this study aimed to investigate the prevalence of depression among staff at various levels of work positions in the academic institution. The objective of the study would also to determine the possible contributing factors (including personal, family as well as job-related factors) that could be the predictors for depression among the staff in academic institutions.

\subsection{Methodology}

This was a cross-sectional study. The staff of a selected academic institution from four different campuses situated in urban areas ( 3 campuses) and suburban area (1 campus) were selected to participate in the study. Those who gave written informed consent were assessed using self-report Pro-forma questionnaires to measure their sociodemographic factors (gender, age, marital status, educational level, level of income), personal factors (personal issue, physical illness and family issue and job-related factors (campus location, job category, duration of service, work promotion, work responsibility, issue with clients or students, level of satisfaction with the superior, conflict with the workmate and condition of workplace facilities). The level of depression was measured using the depression subscales of the Depression, Anxiety, Stress Scale (DASS-21 item). It is a self-report questionnaire which has excellent internal reliabilities with Cronbach's alpha of 0.88 for Depression subscale (Musa, Fadzil, \& Zain, 2007), which has been used in many studies of academic staff in this country (Mukhtar \& Oei, 2011; Noor \& Ismail, 2016). Data were analysed using Statistical Package for the Social Sciences (SPSS) Version 24. Differences between sociodemographic factors, personal factors and job-related factors of staff with and without clinical depression were analysed using Pearson's Chi-Square Test. Simple and multiple logistic regressions were used to determine the possible contributing factors or predictors for depression. This study was approved by the Institutional Ethics Committee.

\subsection{Results}

\subsection{Background of Participants}

A total of 278 staff (Mean \pm SD age: $38.84 \pm 7.85$ years; $44.2 \%$ males) participated in the study. Of the total participants, 173 (62.3\%) were from three campuses located at urban areas in Selangor and $98(35.3 \%)$ were from campus in the suburban area in Johore. The participants were those working at high levels of job position (premier, professional and management) ( $n=94 ; 33.8 \%$ ), and the remaining were support staff and general workers. About two-thirds of the participants ( $n=188 ; 67.6 \%)$ had less than 10 years' duration of service. Of the total participants, $76(27.7 \%)$ had clinical depression (moderate to very severe depressive feelings) and the remaining did not have depression (normal to mild depressive feelings) (Fig. 1).

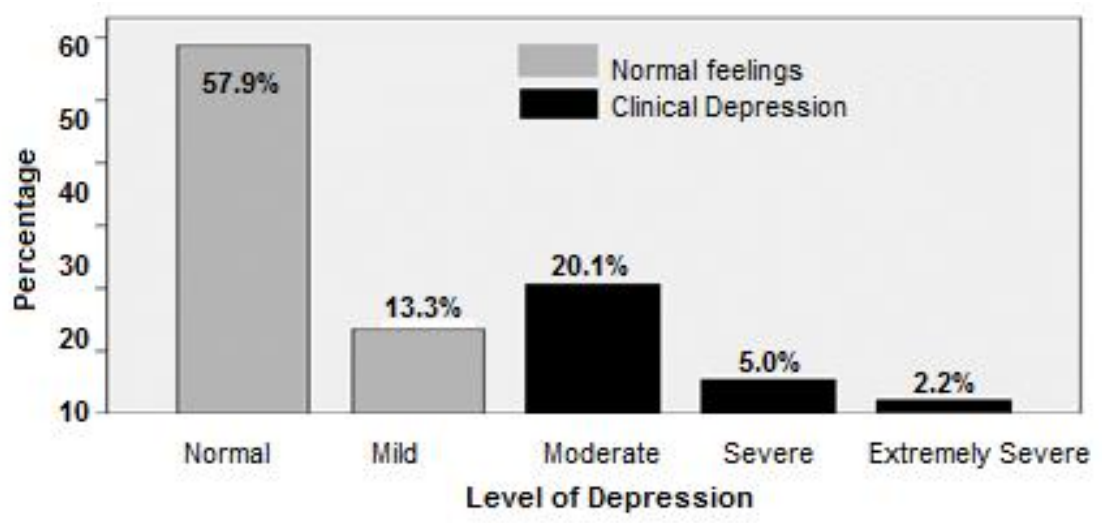

Fig. 1: Percentages of Different Levels of Depression $(n=278)$.

\subsection{Differences between participants with and without clinical depression}

Significant differences between those who were clinically depressed (moderate to very severe depressive feelings) and not clinically depressed (normal to mild depressive feelings) include level of income $\left(X^{2}(1)=4.962, p=0.026\right)$, physical illness $\left(X^{2}(1)=3.971, p=0.046\right)$, campus location $\left(X^{2}(1)=13.252, p=0.000\right)$, job category $\left(X^{2}(1)=8.263, p=0.004\right)$, work responsibility $\left(X^{2}(1)=8.153\right.$, $\left.p=0.004\right)$, level of satisfaction with the superior $\left(X^{2}(1)=6.728, p=0.009\right)$ and inadequate workplace facilities $\left(X^{2}(1)=7.441, p=0.006\right)$. The details of 
differences between participants with and without clinical depression in association with their sociodemographic backgrounds, personal factors and job-related factors are elaborated in Table 1.

Table 1: Differences between participants with and without clinical depression in association with their sociodemographic backgrounds, personal factors and job-related factors

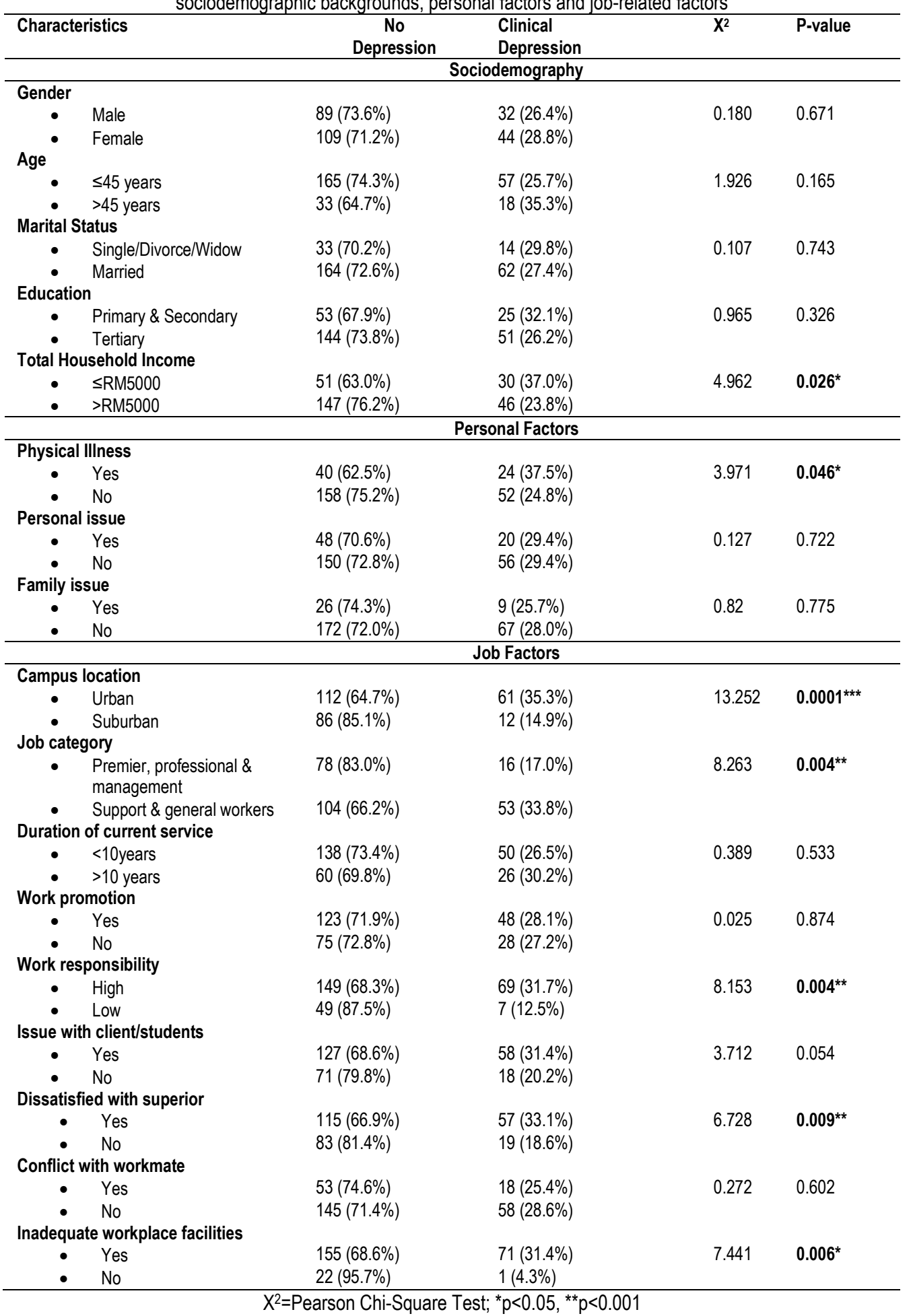

\subsection{Predictors for depression}

Multiple logistic regressions showed that inadequate workplace facilities, job category, campus location and total household income were the predictors for depression among the staff of the academic institution. Even though the presence of physical illness was significantly different between the staff with and without clinical depression, this factor was excluded from the model development because its inclusion resulted in the model became insignificant. We found that inadequate workplace facilities as the strongest predictor for depression (AOR=9.120; $p=0.041 ; 95 \% \mathrm{Cl}=1.099-75.668)$, followed by low-tier job category which had almost four times odds of 
having clinical depression $(\mathrm{AOR}=3.924 ; \mathrm{p}=0.001 ; 95 \% \mathrm{Cl}=1.727-8.915)$. Staff working in the urban area had higher odds of having clinical depression and working in suburban was protective of clinical depression, but the odds were very low $(A O R=0.151 ; p=0.000$; $95 \% \mathrm{Cl}=0.065-0.352)$. Higher household income was a protective factor for clinical depression $(\mathrm{AOR}=0.422 ; \mathrm{p}=0.041 ; 95 \% \mathrm{Cl}=0.184$ $0.965)$. The model is significant as reported by the Omnibus Test $\left(X^{2}=54.224, d f=6, p=0.000\right)$; Nagelkerke $R$ Square test equals to 0.303; Cox \& Snell R Square test equals to 0.212 , and Hosmer \& Lemeshow test equals to 0.252 . It has a specificity of $89.6 \%$ and sensitivity of $52.3 \%$ (Table 2).

Table 2: Predictors for Depression among Staff of Academic Institution

\begin{tabular}{|c|c|c|c|c|c|c|c|c|c|c|}
\hline \multirow{2}{*}{ Predictors } & \multicolumn{5}{|c|}{ Simple logistic regression } & \multicolumn{5}{|c|}{ Multiple logistic regression } \\
\hline & B & OR & P value & & & Adj B & Adj OR & $P$ value & & $\mathrm{Cl}$ \\
\hline Work facilities & 2.310 & 10.007 & 0.025 & 1.332 & 76.241 & 2.210 & 9.120 & $0.041^{*}$ & 1.099 & 75.668 \\
\hline Job category & 0.910 & 2.484 & 0.005 & 1.321 & 4.672 & 1.367 & 3.924 & $0.001^{\text {** }}$ & 1.727 & 8.915 \\
\hline Campus location & -1.189 & 0.320 & 0.000 & 0.170 & 0.602 & -1.889 & 0.151 & $0.000^{* *}$ & 0.065 & 0.352 \\
\hline Total household income & -0.631 & 0.532 & 0.027 & 0.304 & 0.931 & -.864 & 0.422 & $0.041^{*}$ & 0.184 & 0.965 \\
\hline Workplace responsibility & 1.176 & 3.242 & 0.006 & 1.937 & 7.52 & 0.838 & 2.313 & 0.103 & 0.844 & 6.335 \\
\hline Satisfaction with superior & 0.773 & 2.165 & 0.010 & 1.199 & 3,910 & 0.561 & 1.753 & 0.137 & 0.836 & 3.672 \\
\hline
\end{tabular}

Omnibus Test $\left(X^{2}=54.224, d f=6, p=0.000\right)$; Nagelkerke R Square $=0.303 ;$ Cox \& Snell R Square $=0.212$;

Hosmer \& Lemeshow $=0.252$; Specificity $=89.6 \%$; Sensitivity $=52.3 \% ;{ }^{*} p<0.05,{ }^{* *} p<0.001$

\subsection{Discussion}

While background sociodemography such as age, gender, marital status, personal and family issues have been known to precipitate depression in general population (Lorant et al., 2003; Mead, 2002), we highlight that the main predictors of depression among staff in academic institutions are likely to be factors that relate to their work including workplace facilities, job category, total household income and the location of the campus.

In the era of a breakthrough in technology, the academic institution should abreast and be equipped with up-to-date facilities to provide an efficient and smart work environment for the staff. Inadequate resources to facilitate the work process, as documented in this study played a significant role in the genesis of depression among staff in the academic institution. Poorly maintained and inefficient facilities may increase the tendency for staff to develop job stress which in turn precipitates emotional disturbance such as depression. The attribution of low work resources (including inadequate work facilities) is solid that it can independently contribute to depression among workers (Lunau, Wahrendorf, Müller, Wright, \& Dragano, 2018). The importance of the work environment in precipitating depression have also been supported by a 23-years prospective cohort study investigating factors for depression elsewhere (Heinz et al., 2018). In Malaysia, a local study by Yeoh, Tam, Wong, and Bonn (2017) who assessed predictors for depression showed a clear contribution of job environment and depressive symptoms. Hence, the authorities in academic institutions need to provide more supportive and conducive work environment with efficient facilities which function not only for promoting academic progress and enrich scholarly collaboration but also as spaces designed for timeout and quick escape during work time, which in turn can amplify productivity, hence ensures the physical and mental health of the workers (Heinz et al., 2018).

Our study showed that top-level management, professionals and managerial staff reported having less tendency for depression compared to support staff and general workers. This job factor has also been documented as one of the crucial predictors for depression by other local researchers (Manaf et al., 2016; Yeoh et al., 2017), suggesting lack of power to make essential decisions is a source of depression among lower rank staff in academic institutions. In a review of sixteen studies that involved 63000 employees, low decision latitude (apart from high work demand) has been documented to be the strongest predictor for depression among workers (Bonde, 2008). Moreover, it is interesting to highlight that while decision making is one of the vital elements, we found no significant role of gender difference in depression among staff in the studied academic institution. This result is in contrary to the finding of another local study by Fasoro (2018) which found that male staff have a higher tendency for depression. Perhaps, in the academic institution we studied, an equal chance was given to both male and female staff to hold the top-level management and decision-making position. Addressing decision latitude is challenging because it relates to the work description of each staff. Hence, to manage depression among staff, instead of reevaluating work description, authority in the academic institution should use other strategies including positive reinforcement, reward strategies and increase support system for the academic staff (Letellier et al., 2018).

While social scientists are still in disagreement on the role of living environment on status of well-being (Berry \& Okulicz-Kozaryn, 2009; Okulicz-Kozaryn \& Mazelis, 2018), our study supported the traditional and widespread belief that financial security and living in a suburban area may protect one from psychological issues. Our finding is in keeping with the result of a recent systematic review that evaluated 21 studies on the impact of household financial strain on psychological well-being (French \& Vigne, 2019). The study showed that having a financial issue may increase the tendency for one to have depression. Perhaps, mediating factors including personal factors such as difficulty to manage direct financial obligation (such as a mortgage, medical or educational expenses, and general consumer debt) and indirect financial requirement (such as family size, number of children and marital status) (Sinclair \& Cheung, 2016) play significant contribution to depression. Moreover, our study agreed that working in a suburban area is better, perhaps because of low population density, better social organization, healthier social integration as well as better social support in suburban area would prevent staff in academic institution from having psychological issues such as depression (Berry \& Okulicz-Kozaryn, 2009; OkuliczKozaryn \& Mazelis, 2018). 


\subsection{Conclusion}

The findings of this study are relevant to inform authorities in academic institutions of the predictors of depression among their staff. The job-related factors including inadequate workplace facilities, low-tier job category or work position that allow control and decision making, low income and financial insecurity, as well as the unfavourable location of the institution which underpin depression among staff in academic institutions, should be addressed comprehensively as early as possible to prevent complications. A concerted effort from the staff and higher authorities is crucial to address this issue. Nevertheless, we would like to inform that the study was limited by its design and suggest a more robust prospective study, using diagnostic assessment and larger sample size to determine the causal factors for depression among the staff of academic institutions. We are aware that many other personal, job and environmental factors that could influence depression among staff in academic institutions that have not been included in this study.

\section{Acknowledgements}

This study was funded by UiTM BESTARI Grant [600-IRMI/DANA 5/3/BESTARI (KY) (001/2018)] awarded to the corresponding and first authors. We would like to express our appreciation to all study participants who had volunteered to participate in this study and all agencies, staff and postgraduate students who had contributed to the Health Screening Programs.

\section{References}

Ahsan, N., Abdullah, Z., Fie, D. Y. G., \& Alam, S. S. (2009). A study of job stress on job satisfaction among university staff in Malaysia: Empirical study. European journal of social sciences, 8(1), 121-131.

Berry, B. J., \& Okulicz-Kozaryn, A. (2009). Dissatisfaction with city life: A new look at some old questions. Cities, 26(3), 117-124.

Bonde, J. P. E. (2008). Psychosocial factors at work and risk of depression: a systematic review of the epidemiological evidence. Occupational and environmental medicine, 65(7), 438-445

Fasoro, A. (2018). Prevalence and Associated Factors of Current Depressive Symptoms among Staff of a Public University in Malaysia. Online Journal of Health and Allied Sciences, 16(4).

French, D., \& Vigne, S. (2019). The causes and consequences of household financial strain: A systematic review. International Review of Financial Analysis, 62, 150156.

Heinz, A. J., Meffert, B. N., Halvorson, M. A., Blonigen, D., Timko, C., \& Cronkite, R. (2018). Employment characteristics, work environment, and the course of depression over 23 years: Does employment help foster resilience? Depression and anxiety, 35(9), 861-867.

Ismail, A., Yao, A., \& Yunus, N. K. Y. (2009). Relationship Between Occupational Stress and Job Satisfaction: An Empirical Study in Malaysia. Romanian Economic Journal, 12(34)

January, J., Madhombiro, M., Chipamaunga, S., Ray, S., Chingono, A., \& Abas, M. (2018). Prevalence of depression and anxiety among undergraduate university students in low-and middle-income countries: a systematic review protocol. Systematic reviews, 7(1), 57.

Karasek Jr, R. A. (1979). Job demands, job decision latitude, and mental strain: Implications for job redesign. Administrative science quarterly, 285-308.

Lammerts, L., Schaafsma, F. G., Eikelenboom, M., Vermeulen, S. J., van Mechelen, W., Anema, J. R., \& Penninx, B. W. (2016). Longitudinal associations between biopsychosocial factors and sustainable return to work of sick-listed workers with a depressive or anxiety disorder. Journal of occupational rehabilitation, 26(1), 70-79.

Lerner, D., \& Henke, R. M. (2008). What does research tell us about depression, job performance, and work productivity? Journal of Occupational and Environmental Medicine, 50(4), 401-410.

Letellier, M.-C., Duchaine, C., Aubé, K., Talbot, D., Mantha-Bélisle, M.-M., Sultan-Taïeb, H., .. Brisson, C. (2018). Evaluation of the Quebec Healthy Enterprise Standard: effect on adverse psychosocial work factors and psychological distress. International journal of environmental research and public health, $15(3), 426$.

Lorant, V., Deliège, D., Eaton, W., Robert, A., Philippot, P., \& Ansseau, M. (2003). Socioeconomic inequalities in depression: a meta-analysis. American journal of epidemiology, 157(2), 98-112.

Lunau, T., Wahrendorf, M., Müller, A., Wright, B., \& Dragano, N. (2018). Do resources buffer the prospective association of psychosocial work stress with depression? Longitudinal evidence from ageing workers. Scandinavian journal of work, environment \& health, 44(2), 183-191.

Manaf, M. R. A., Qureshi, A. M., Lotfizadeh, M., Ganasegeran, K., Yadav, H., \& Al-Dubai, S. (2016). Factors associated with anxiety and depression among outpatients in Malaysia: A cross-sectional study. Malaysian Journal of Public Health Medicine, 16(3), 181-187.

Mead, D. E. (2002). Marital distress, co - occurring depression, and marital therapy: A review. Journal of marital and family therapy, 28(3), 299-314.

Milner, A., Witt, K., LaMontagne, A. D., \& Niedhammer, I. (2018). Psychosocial job stressors and suicidality: a meta-analysis and systematic review. Occupational and environmental medicine, $75(4), 245-253$

Ministry of Health Malaysia. (2019). Management of Depressive Disorder ( Second Edition). Retrieved 26 September 2019 from http://www.moh.gov.my/moh/resources/Penerbitan/CPG/1)_CPG_Management_Significant_Depressive_Disorder_(Second_Edition).pdf. 
Mukhtar, F., \& Oei, T. P. (2011). A review of assessment and treatment for depression in Malaysia. Depression research and treatment, 2011.

Musa, R., Fadzil, M. A., \& Zain, Z. (2007). Translation, validation and psychometric properties of Bahasa Malaysia version of the Depression Anxiety and Stress Scales (DASS). ASEAN Journal of Psychiatry, 8(2), 82-89.

Mustapha, N. (2013). The influence of financial reward on job satisfaction among academic staffs at public universities in Kelantan, Malaysia. International Journal of Business and Social Science, $4(3)$.

Noor, A., \& Ismail, N. H. (2016). Occupational stress and its associated factors among academician in a research university, Malaysia. Malaysian Journal of Public Health Medicine, 16(1), 81-91.

Noordin, F., \& Jusoff, K. (2009). Levels of job satisfaction amongst Malaysian academic staff. Asian social science, 5(5), $122-128$.

Okulicz-Kozaryn, A., \& Mazelis, J. M. (2018). Urbanism and happiness: A test of Wirth's theory of urban life. Urban Studies, 55(2), $349-364$.

Sinclair, R. R., \& Cheung, J. H. (2016). Money matters: Recommendations for financial stress research in occupational health psychology. Stress and Health, 32(3), 181193

Van der Doef, M., \& Maes, S. (1999). The job demand-control (-support) model and psychological well-being: a review of 20 years of empirical research. Work \& Stress, 13(2), 87-114.

World Health Organization. (2019). Mental Health; Depression, Let's talk. Retrieved from https://www.who.int/mental_health/management/depression/en/

Yeoh, S. H., Tam, C. L., Wong, C. P., \& Bonn, G. (2017). Examining depressive symptoms and their predictors in Malaysia: Stress, locus of control, and occupation. Frontiers in psychology, 8, 1411 . 